\title{
Does the awareness of the patient about the amount of daily salt consumption decrease his/her salt intake?
}

\section{Hastanın günlük ne kadar tuz tükettiğini bilmesi tuz tüketimini azaltır mı?}

\author{
Muammer BíLici ${ }^{1}$, Fatih YILMAZ ${ }^{2}$, Sevil Uygun iLiKHAN ${ }^{1}$, Ali BORAZAN ${ }^{3}$
}

ABSTRACT

In the present study, we investigated the impact of the awareness of the daily salt intake on dietary salt consumption in patients with primary hypertension. One hundred and fifty-four patients (male, 80, and female, 74) treated with the established diagnosis of hypertension, and also followed up after providing information about salt consumption were enrolled in the present study. Urinary sodium was measured in 24-hour urine samples, and the patients were informed about their salt consumption together with their laboratory results. Three months later urinary sodium levels were measured in 24-hour urine samples again. Changes in blood pressure, and salt consumption were compared statistically. Mean age of 154 patients enralled in the study was $48.4 \pm 14.9$ years. It was observed that the patients had not known their daily salt consumption. Their daily salt intake had been $12.6 \pm 4.8 \mathrm{~g}$, while their daily intake dropped to $7.4 \pm 3.7 \mathrm{~g}$ after control of salt intake with monitorization of urinary sodium. Baseline systolic/diastolic blood pressure $(p=0.024$ and $=0.034$, respectively) values decreased, in parallel with reduction in daily salt intake $(12.6 \pm 4.8 \mathrm{~g} /$ day to $7.4 \pm 3.7 \mathrm{~g} /$ day) $(p<0.001)$. We recommend providing information to the patients routinely about the amount of daily salt intake so as to raise, and increase awareness in patients with intractable blood pressure. öz

Bu çalışmada, hipertansiyonlu hastalarda günlük tuz tüketim miktarının bilinmesinin oluşturacağı farkındalığın tuz alımı üzerine etkisi araştırıldı. Çalışmaya hipertansiyon tanısı konularak tedavi başlanan ve tuz tüketimi ile ilgili bilgiler verildikten sonra takibi yapılan 154 (80 E, 74K) hasta alındı. Hastalara 24 saatlik idrarda Na ölçümü yapılarak ne kadar tuz tükettikleri laboratuvar sonuçlarıyla birlikte anlatıldı. Üç ay sonra 24 saatlik idrarda yine Na kontrolü yapıldı. Kan basıncı değişiklikleri ve tuz tüketimi istatistiksel olarak karşılaştırıldı. Çalışmaya alınan 154 hastanın yaş ortalaması $48,4 \pm 14,9$ yıl idi. Hastaların ne kadar tuz tüketiklerini bilmediklerinde ortalama 12,6ะ4.8 g tuz tüketirken, 24 saatlik idrarla birlikte kontrolünü gören hastalarda günlük tuz tüketimi $7,4 \pm 3,7$ g'a düştüğü görüldü $(p<0,001)$. Tuz tükemindeki azalmaya paralel olarak başlangıç sistolik/diastolik kan basıncı değerleri $145,46 \pm 18,2 / 86,6 \pm 8,6 \mathrm{mmHg}^{\prime}$ dan $136,4 \pm 11,6 / 81,8 \pm 6,8 \mathrm{mmHg}$ 'a geriledi (sırasıyla; $p=0,024$ ve $p=0,034$ ). Hastaların günlük tuz tüketim miktarını bilmesinin, kan basıncı kontrolu yapılamayan olgularda rutin olarak uygulanmasını farkındalığın arttırılması için önermekteyiz.
GiRiş

Diyet içeriğindeki tuz miktarı artışı kan basıncında değişiklik yapabilecek önemli faktörlerden birisidir. Farklı toplumları kapsayan geniş epidemiyolojik çalışmalar, kişi başı diyetle alınan tuz miktarındaki artış ile ölçülen kan basıncı değerleri arasında pozitif bir ilişkinin varlığını göstermiştir. Tuz tüketiminin yüksek olduğu toplumlarda hipertansiyon (HT) sıklığı en yüksek iken, çok düşük miktarlarda tuz tüketen toplumlarda bu sıklık en düşük düzeyde görülmektedir ${ }^{1,2}$. Dünya Sağlık Örgütü (DSÖ) diyetle günlük tuz tüketiminin erişkinlerde $<5$ g olması gerektiğini önermektedir ${ }^{3}$. Türk Hipertansiyon ve Böbrek Hastalıkları Derneği tarafından 2008 yılında yapılan SALTÜRK çalışmasında, Türkiye'de günlük tuz alımının erişkin bireylerde kişi başı yaklaşık $18 \mathrm{~g}$ olduğu bildirilmiştir ${ }^{4}$. Bireyin günlük tuz tüketim miktarını tespit etmede ise 24 saatlik idrar sodyum değerinin saptanması uygun bir belirteç olarak önerilmektedir ${ }^{1}$.

Received: 19.10 .2016

Accepted: 11.11 .2016

${ }^{1}$ Bulent Ecevit University School of Medicine, Department of Internal Medicine

2Zonguldak Ataturk Goverment Hospital, Department of Nephrology

${ }^{3}$ Bulent Ecevit University School of Medicine, Department of Nephrology

Yazışma adresi: Muammer Bilici, Bulent Ecevit University School of Medicine, Department of Internal Medicine, Zonguldak

e-mail: drmbilici@hotmail.com 
Yüksek miktarda tuz tüketiminin, kalp-damar hastalıkları ve inme gibi hastalıkların da görülme riskini arttırdığı bilinmektedir. Bu amaçla yetişkinlerde günlük tuz tüketiminin azaltılması birey ve toplum sağlığı açısından önemli bir yaklaşımdır. Diyetteki tuz miktarının günde $1 \mathrm{~g}$ azaltılması felçleri \%5, kalp krizlerini \%3, günde $9 \mathrm{~g}$ azaltılması ise felçleri \%34, kalp krizlerini \%24 oranında azalttığı tespit edilmiştir ${ }^{5}$.

Biz bu çalışmada, HT tanılı hastalarda günlük tüketilen tuz miktarının bilinmesinin oluşturacağı farkındalığın diyetle günlük tuz tüketiminin azaltılmasına yönelik katkısını değerlendirmeyi amaçladık.

\section{GEREÇ ve YÖNTEMLER}

Primer HT tanısıyla takip edilen 154 hasta çalışmaya alındı. Çalışmaya dahil edilme kriterleri, arteriyel kan basıncı $\geq 140 / 90 \mathrm{mmHg}$ olan veya en az bir antihipertansif ilaç kullanan primer HT hastası çalışmaya dahil edildi. İskemik kalp hastalığı, serebrovasküler hastalık, böbrek veya karaciğer yetmezliği, tiazid grubu diüretik içeren antihipertansif kullananlar veya herhangi bir ek tedavi almakta olan hastalar çalışmaya alınmadı.

Çalışmaya dahil edilen hastaların, cinsiyet, yaş, boy, ağırlık, vücut kitle indeksi (VKi), hipertansiyon süresi, sistolik (SKB) ve diastolik kan kasıncı (DKB) değerleri kaydedildi. Günlük tuz tüketimi, başlangıç ve 3 ay sonrasında 24 saatlik idrar sodyum atılım miktarı kullanılarak belirlendi ${ }^{1}$. Vücut Kitle İndeksi $=$ Ağırlık (kg) / Boy $(\mathrm{m})^{2}$ formülü ile hesaplandı.

Hastaların tamamına daha önce yaşam tarzı değişikliği ve beslenme desteği eğitimi kapsamında tuz kısıtlaması standart eğitimi verilmiş olmasına rağmen, tuz tüketim miktarları ölçülerek yine yanında en az bir yakını ile birlikte bilgilendirme yapıldı ${ }^{6,7}$. Hastaların 3 ay sonra bakılan tuz tüketim miktarları ve SKB ile DKB değişiklikleri değerlendirildi.

Bu çalışma protokolunun Dünya Tıp Birliği'nin Helsinki Bildirgesi'ne (2013) uygunluk onayı Bülent Ecevit Üniversitesi Tıp Fakültesi Klinik Araştırmalar Etik Kurulu'ndan alınmıştır.

\section{İstatistiksel Analiz}

Çalışmanın istatistiksel analizleri SPSS 19.0 paket programında yapılmıştır. Kategorik değişkenler frekans ve yüzde ile sürekli değişkenler ortalama ve standart sapma değerleriyle verilmiştir. Sürekli değişkenlerin normal dağılıma uygunluğu Shapiro Wilk testi ile incelenmiştir. Sürekli değişkenlerin 2 grup karşılaştırmalarında bağımsız örneklem t testi kullanılmıştır. Çalışmadaki tüm istatistiksel karşılaştırmalarda $p$ değeri 0,05'in altındaki sonuçlar istatistiksel olarak anlamlı kabul edilmiştir.

\section{BULGULAR}

Hastaların 74'ü kadın (\%48), 80'i erkek (\%52) olup, yaş, hastalık süresi ve VKi ortalaması sırasıyla $48,4 \pm 14,9$ $\mathrm{yll}, 62,3 \pm 23,3$ ay ve $29,6 \pm 3,9 \mathrm{~kg} / \mathrm{m}^{2}$ olarak tespit edildi (Tablo 1). Başlangıçta SKB ortalaması $145,46 \pm 18,2$ $\mathrm{mmHg}$, DKB ortalaması $86,6 \pm 8,6 \mathrm{mmHg}$ bulundu. Yirmi dört saatlik idrarda Na 214,2 $\pm 81,6 \mathrm{mEq} /$ gün idi. Kontrolde 24 saatlik idrarda $\mathrm{Na}$ 125,8 $\pm 62,9 \mathrm{mEq} / \mathrm{gün}$ ölçüldü. Hastaların ne kadar tuz tükettiklerini bilmediklerinde ortalama 12,6 $\pm 4,8$ g/gün (Erkek $=13,3 \pm 4,1$ ve Kadın=11,9 $\pm 3,6$ ) tuz tüketirken 24 saatlik idrarla birlikte kontrolünü gören hastalarda günlük tuz tüketimi $7,4 \pm 3,7 \mathrm{~g} /$ güne (Erkek=7,7 $\pm 3,9$ ve Kadın=7,1 $\pm 3,2$ ) düştüğü görüldü $(p<0,001)$. Erkek ve kadın arasında

Tablo 1. Hipertansiyon hastalarının demografik, klinik ve laboratuvar özellikleri.

\begin{tabular}{|c|c|c|c|}
\hline & \multicolumn{2}{|c|}{$\begin{array}{l}\text { Hipertansif hastalar } \\
\qquad(n=154)\end{array}$} & p \\
\hline Yaş (yıl) & \multicolumn{2}{|c|}{$48,4 \pm 14,9$} & \\
\hline Cinsiyet (E/K) & \multicolumn{2}{|c|}{$80 / 74$} & \\
\hline Hastalık süresi (ay) & \multicolumn{2}{|c|}{$62,3 \pm 23,3$} & \\
\hline \multirow[t]{2}{*}{ VKi $\left(\mathrm{kg} / \mathrm{m}^{2}\right)$} & \multicolumn{2}{|c|}{$29,6 \pm 3,9$} & \\
\hline & 0. ay & 3. ay & \\
\hline $\mathrm{SKB}(\mathrm{mmHg})$ & $145,46 \pm 18,2$ & $136,4 \pm 11,6$ & 0,024 \\
\hline $\mathrm{DKB}(\mathrm{mmHg})$ & $86,6 \pm 8,68$ & $81,8 \pm 6,8$ & 0,034 \\
\hline Günlük tuz tüketimi (g/gün) & $12,6 \pm 4,8$ & $7,4 \pm 3,7$ & $<0,001$ \\
\hline $\begin{array}{l}24 \text { saatlik idrarda } \mathrm{Na} \text { atlımı } \\
\text { (mEq/gün) }\end{array}$ & $214,2 \pm 81,6$ & $125,8 \pm 62,9$ & $<0,001$ \\
\hline
\end{tabular}

E: Erkek, K: Kadın, VKi: Vücut Kitle Indeksi, SKB: Sistolik Kan BasınCI, DKB: Diastolik Kan Basıncı 
eğitim öncesi ve sonrası tuz tüketimleri karşılaştırıldığında gruplar arasında anlamlı fark saptanmadı $(p=0,935)$. Kontrolde SKB ortalaması $136,4 \pm 11,6$ $\mathrm{mmHg}$ ve DKB ortalaması $81,8 \pm 6,8 \mathrm{mmHg}(p<0,001)$ bulundu.

\section{TARTIŞMA}

Toplumlara göre tuz tüketim miktarı değişmekle birlikte, çoğu ülkede günlük tuz tüketimi 9-12 g/gün aralığındadır. Türkiye'de ise ne yazık ki kişi başına tuz tüketimi, gelişmiş ülkelere kıyaslandığında oldukça yüksektir. Yapılan geniş epidemiyolojik çalışmalar, günlük tuz alımı ile kan basıncı arasında çok yüksek oranda ve anlamlı bir ilişki saptamışlardır ${ }^{1,2,4}$. Hipertansif hastalarda tuz kısıtlaması, kan basıncı kontrolü sağlanmasında kabul görmüş yaşam tarzı değişikliklerinin başında gelmektedir. Günlük tuz tüketiminin 5-6 g düzeyine düşürülmesinin kan basıncında anlamlı azalma sağlamasının yanında uzun dönemde belirlenecek hedefin $3 \mathrm{~g} / g u ̈ n$ olması önerilmektedir ${ }^{8,9}$.

Hipertansif ve normotansiflerde, tuz tüketimindeki azalma ile kan basıncı değişikliğinin değerlendirildiği bir meta-analizin sonuçlarına göre hipertansiflerde günlük alınan tuz miktarındaki ortalama 4,6 g azalma SKB' da 4,96 $\pm 0,40 \mathrm{mmHg}$ ve DKB' $^{\prime}$ da $2,73 \pm 0,24$ $\mathrm{mmHg}$ düşüşe neden olmaktadır. Tuz miktarındaki azalma 6 g seviyesinde ise SKB ve DKB'da beklenen düşüşün sırasıyla 7,11 ve $3,88 \mathrm{mmHg}$ olacağı bildirilmiştir. Tuz tüketimi azalmasının, normotansiflerde de benzer sonuçları dikkat çekmektedir ${ }^{10}$. Tedavi almamış 20 esansiyel HT hastasını içeren randomize çift kör çapraz başka bir çalışmada ise, birer aylık sürelerde hastaların günlük tuz tüketimi sırayla $11,2 \mathrm{~g}, 6,4$ $\mathrm{g}$ ve $2,9 \mathrm{~g}$ düzeyine azaltılmıştır. Tuz tüketimindeki azalmaya paralel olarak takipte kan basınçları sırasıyla 163/100 mm Hg'den 155/95 mm Hg'a ve sonuçta 147/91 mm Hg'ya gerilemiştir. Çalışma tamamlandıktan bir yıl sonra düşük tuz alımına devam edilen bu hastalardan 16'sında ilaçsız kan basıncı kontrolü devamı sağlandığı gözlemlenmiştir. Hastalarda günlük 3,2 g tuz tüketimiyle ortalama kan basıncı 142/87 $\mathrm{mmHg}$ olarak tespit edilmiştir ${ }^{11}$.
Tuz alımı kısıtlamasının, kan basıncı kontrolü üzerine olumlu etkilerini gösteren çalışmalar ortaya koymaktadır ki günlük ortalama tuz tüketiminin $6 \mathrm{~g}$ düzeylerine çekilmesinin kan basıncı üzerine anlamlı derecede yararlı etkisi olacaktır.

Bu çalışmada, daha önce tuz tüketiminin azaltılması için beslenme danışmanlığı verilmiş HT hastalarında diyet uyumu ve farkındalığı arttırması açısından diyetle alınan tuz miktarı ölçülerek hastalara bilgilendirme yapıldı. Başlangıç günlük tuz tüketimi $12,6 \pm 4,8$ g iken, 3. ayda 7,4 $\pm 3,7$ g olarak saptandı. Tuz tükemindeki azalmaya paralel olarak SKB ve DKB değerlerinde anlamlı düşüş izlendi (Başlangıç SKB/ DKB değerleri $145,46 \pm 18,2 / 86,6 \pm 8,6 \mathrm{mmHg}$ 'dan $136,4 \pm 11,6 / 81,8 \pm 6,8$ mmHg'a geriledi). Bu sonuçlar, tuz tüketiminin azaltılması için verilecek beslenme eğitiminde hastaların günlük tuz alım miktarlarını bilmelerinin farkındalık oluşturarak diyet uyumunu arttırdığını göstermektedir.

Çalışmanın tek merkezli bir çalışma olması ve hasta popülasyonun nispeten az olması kısıtlamalarındandır. Bir diğeri kısıtlama ise standart eğitim verilen hastalardan oluşan kontrol grubumuzun olmamasıdır. Kliniğimizde son bir yıldır yaşam tarzı değişikliği önerisi veya antihipertansif tedavisi altında hipertansif seyreden hastalara standart eğitim ile birlikte günlük tuz tüketimleri bildirilmektedir.

Tuz tüketimi ile HT insidansında artış arasında gösterilmiş olan kuvvetli ilişki sonucunda, tuz tüketiminin azaltılmasına yönelik programlar yapılmaktadır. Bu amaçla, ülkemizde de Sağlık Bakanlığınca aşırı tuz tüketiminin azaltılması programı yürütülmektedir. Özellikle, HT hastalarının büyük çoğunluğunda günlük tuz tüketiminin yüksek miktarlarda devam ediyor olması, tuz kısıtlaması sağlanmasının kan basıncı kontrolü için üzerinde durulması gereken bir yaklaşım olduğu anlaşılmaktadır ${ }^{5}$.

\section{SONUÇ}

Hipertansif hastalarda kan basıncı kontrolünün kolaylaştırılması için tuz tüketimi azaltımına yönelik verile- 
cek beslenme eğitiminde günlük tuz tüketim miktarının hasta tarafından bilinmesi farkındalık oluşturarak diyet uyumunu arttıracaktır.

\section{KAYNAKLAR}

1. Elliott P, Stamler J, Nichols R, et al. Intersalt revisited: further analyses of 24 hour sodium excretion and blood pressure within and across populations. Intersalt Cooperative Research Group. BMJ 1996;312(7041):1249-53.

https://doi.org/10.1136/bmj.312.7041.1249

2. Stamler J, Elliott P, Dennis B, et al. INTERMAP Research Group. INTERMAP: background, aims, design, methods, and descriptive statistics (nondietary). J Hum Hypertens 2003;17(9):591-608. https://doi.org/10.1038/sj.jhh.1001603

3. Guideline: Sodium Intake for Adults and Children. Geneva: World Health Organization; 2012.

4. Erdem $\mathrm{Y}$, Arici M, Altun B, ve ark. The relationship between hypertension and salt intake in Turkish population: SALTURK study. Blood Press 2010;19(5):313-8.

https://doi.org/10.3109/08037051003802541

5. Sağ ıık Bakanlığı Türkiye Halk Sağlığı Kurumu Türkiye Aşırı Tuz
Tüketiminin Azaltılması Programı 2011-2015.

6. Dickinson HO, Mason JM, Nicolson DJ, et al. Lifestyle interventions to reduce raised blood pressure: a systematic review of randomized controlled trials. J Hypertens 2006;24(2):215-33. https://doi.org/10.1097/01.hjh.0000199800.72563.26

7. Mahtani KR. Simple advice to reduce salt intake. Br J Gen Pract 2009;59(567):786-7. https://doi.org/10.3399/bjgp09X472755

8. He FJ, Li J, Macgregor GA. Effect of longer term modest salt reduction on blood pressure: Cochrane systematic review and meta-analysis of randomised trials. BMJ 2013;346:f1325. https://doi.org/10.1136/bmj.f1325

9. National Institute for Health and Clinical Excellence (NICE). Guidance on the prevention of cardiovascular disease at the population level. NICE, 2010.

10. He FJ, MacGregor GA. Effect of modest salt reduction on blood pressure: a meta-analysis of randomized trials. Implications for public health. J Hum Hypertens 2002;16(11):761-70. https://doi.org/10.1038/sj.jhh.1001459

11. MacGregor GA, Markandu ND, Sagnella GA, Singer DR, Cappuccio FP. Double-blind study of three sodium intakes and long-term effects of sodium restriction in essential hypertension. Lancet 1989;2(8674):1244-7. https://doi.org/10.1016/S0140-6736(89)91852-7 